\title{
On the photophysical behaviour of 4-halo-5-phenylisoxazoles
}

\author{
Sofia M. Fonseca, Hugh D. Burrows *, Cláudio M. Nunes, \\ Teresa M.V.D. Pinho e Melo, António M.d'A. Rocha Gonsalves \\ Departamento de Química, Universidade de Coimbra, PT-3004-535 Coimbra, Portugal
}

Received 10 June 2005; in final form 4 August 2005

Available online 2 September 2005

\begin{abstract}
Detailed spectral and photophysical properties of 4-halo-5-phenylisoxazoles in cyclohexane solutions are presented, including measurements of energies of lowest excited singlet and triplet states, fluorescence quantum yields, lifetimes, phosphorescence and triplet-singlet difference absorption spectra. Upon addition of ethanol, loss of vibrational structure is observed in fluorescence spectra and attributed to formation of isoxazole-ethanol aggregates. The relevance of these properties to the photochemical and thermal reactivity of these systems is discussed.
\end{abstract}

(c) 2005 Elsevier B.V. All rights reserved.

\section{Introduction}

Isoxazoles are an important series of compounds which possess interesting pharmacological properties [1]. In addition, they have real and potential application in areas as diverse as agrochemicals [1], electron-transporting materials for molecular electronics [2] and liquid crystalline materials [3]. They undergo a variety of thermal and photochemical reactions, which have been reviewed and discussed $[1,4,5]$. However, in spite of this interest, only a modest amount of data has been presented on the UV/visible spectral properties of isoxazoles (see, for example, [6-8]), a few theoretical calculations on electronic structure at various levels of sophistication have been reported $[5,8-10]$ and apart from a few reported fluorescence spectra [11] very little is known about their photophysical behaviour. This information is vital for understanding the reactivity patterns in these systems.

We have chosen the methyl 4-halo-5-phenylisoxazole-3carboxylates 1 and 2 as model compounds, Scheme 1, and presented a detailed photophysical study in cyclohexane solutions. In addition, results on their interaction with ethanol have been studied.

\footnotetext{
* Corresponding author. Fax: +351 239827703.

E-mail address: burrows@ci.uc.pt (H.D. Burrows).
}

\section{Experimental}

The 4-halo-5-phenylisoxazoles were synthesised by thermolysis of haloazidoalkenes and 2-halo- $2 \mathrm{H}$-azirines. Details of their synthesis and characterisation are given elsewhere [12]. The solvents were purified by standard procedures.

Absorption and fluorescence spectra were recorded on a Shimadzu UV-2100 and a Jobin-Ivon SPEX Fluorolog 322 spectrometer, respectively. All the fluorescence spectra were corrected for the wavelength response of the system. Fluorescence quantum yields were measured using bithiophene ( $\phi_{\mathrm{F}}=0.014$ in cyclohexane) as standard [13].

Fluorescence decays were measured using a home-built TCSPC apparatus with a $\mathrm{N}_{2}$ filled IBH 5000 coaxial flash lamp as excitation source, Jobin-Ivon monochromator, Philips XP2020Q photomultiplier, and Canberra instruments TAC and MCA. The fluorescence decays were analysed employing the method of modulating functions [14].

Phosphorescence measurements were made in 3-methylpentane glasses at $77 \mathrm{~K}$ using a SPEX 1934D phosphorimeter accessory with a Fluorolog 3-22 spectrometer. Attempts were made to obtain information on the nature of the excited state by polarized excitation spectra. However, these were inconclusive. 


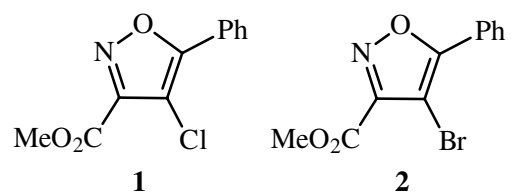

Scheme 1. Structures of the methyl 4-halo-5-phenylisoxazole-3-carboxylates used in this work.

Flash photolysis experiments were performed with an Applied Photophysics laser flash photolysis equipment pumped by the fourth harmonic $(266 \mathrm{~nm})$ of a Nd:YAG laser (Spectra Physics). Transient spectra were obtained by monitoring the optical density change at $5-10 \mathrm{~nm}$ intervals over the $250-600 \mathrm{~nm}$ range and averaging at least 10 decays at each wavelength. First-order kinetics were observed for the decay of the lowest triplet state in all cases.

\section{Results and discussion}

Absorption spectra of the isoxazoles 1 and $\mathbf{2}$ in cyclohexane showed similar intense, broad absorptions around $300 \mathrm{~nm}$, with poorly resolved vibrational structure, and a weaker band near $250 \mathrm{~nm}$ (Fig. 1). Structured fluorescence spectra (Fig. 1) were observed with the two compounds, and show a vibronic spacing $1450 \pm 200 \mathrm{~cm}^{-1}$, which can be compared with a series of bands between 1436 and $1530 \mathrm{~cm}^{-1}$ seen in the infrared and Raman spectra of isoxazoles, assigned to ring stretching vibrations [15-17]. For the parent isoxazole, the first absorption band is around $210 \mathrm{~nm}$, and the lowest excited state is suggested to have ${ }^{1} \pi, \pi^{*}$ character [8]. This maximum is slightly red-shifted on alkyl substitution of the isoxazole ring, but more pronounced shifts are observed with phenyl substituents in the 3- or 5-positions [18]. From the overlap of absorption and emission spectra, and the magnitude of the molar extinction coefficient, both the fluorescence and the lowest energy absorption band are attributed to a transition involving a common ${ }^{1} \pi, \pi^{*}$ lowest excited state at

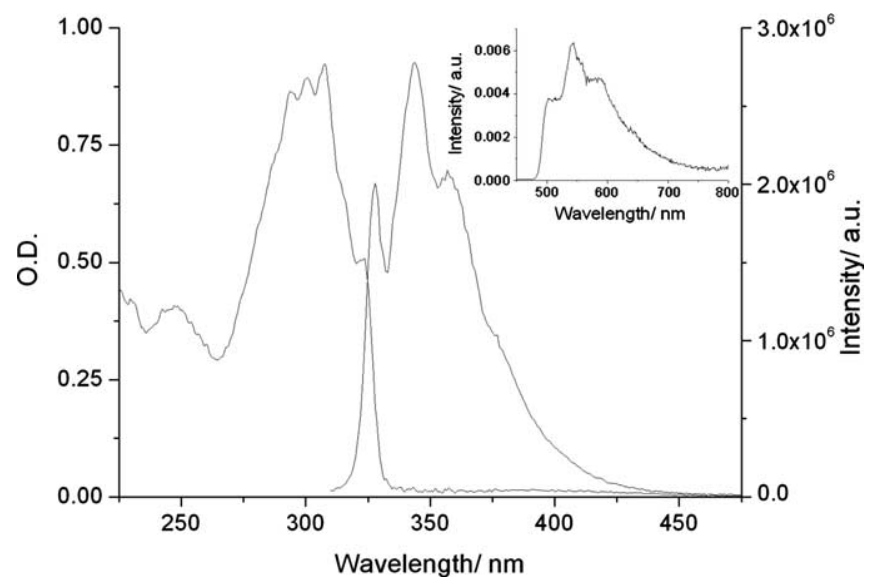

Fig. 1. Absorption (left), fluorescence (right) and phosphorescence (inset) spectra of isoxazole 2 in cyclohexane solution. Excitation was at the absorption maximum $(307 \mathrm{~nm})$.
$30800 \mathrm{~cm}^{-1}(3.82 \mathrm{eV})$. The energy of this was determined from the intersection of the absorption and emission spectra. The marked red-shift in absorption of $\mathbf{1}$ and $\mathbf{2}$ relative to both isoxazole and phenyl moieties indicates extensive conjugation between the two rings. Homolytic cleavage of the $\mathrm{N}-\mathrm{O}$ bond in isoxazoles to form biradicals has been proposed to explain the formation of $2 \mathrm{H}$-azirines on photolysis and thermolysis [1]. However, the observation of a bonding ${ }^{1} \pi, \pi^{*}$ lowest excited state for the phenylisoxazoles indicates that direct photodissociation is unlikely, and suggests that more than one step must be involved in this case. Further, the observation of a lowest ${ }^{1} \pi, \pi^{*}$ excited state contrasts with azabenzenes and other N-heteroaromatic systems, where the lowest excited state has ${ }^{1} \mathrm{n}, \pi^{*}$ character [19-21]. Observation of the first ${ }^{1} n, \pi^{*}$ state remains elusive [18].

To further characterise the excited state behaviour, a detailed photophysical study of compounds $\mathbf{1}$ and $\mathbf{2}$ was made in cyclohexane solutions, including measurements of fluorescence quantum yields, lifetimes, phosphorescence and characterisation of triplet state by flash photolysis. The relatively high fluorescence quantum yield of the chloro compound is consistent with the lowest singlet state having $\pi, \pi^{*}$ character. The triplet energies were determined from the onset of the phosphorescence to be $20700 \mathrm{~cm}^{-1}$ $(2.57 \mathrm{eV})$. The $\mathrm{S}_{1}-\mathrm{T}_{1}$ splitting is also consistent with both the singlet and triplet states having $\pi, \pi^{*}$ character.

Marked decreases in fluorescence quantum yield and lifetime were seen on going from the chloro to the bromo derivative. This is typical of aromatic compounds, and is due to the larger heavy atom effect of bromo compared with chloro substituent [22], leading to increased intersystem crossing from the lowest singlet state to the triplet manifold. A similar effect explains the shorter phosphorescence lifetime of $\mathbf{2}$ compared with $\mathbf{1}$. Since triplet states have been proposed as intermediates in the photochemistry of various 1,2-benzisoxazoles [23], we have further characterised these by flash photolysis. We have excited

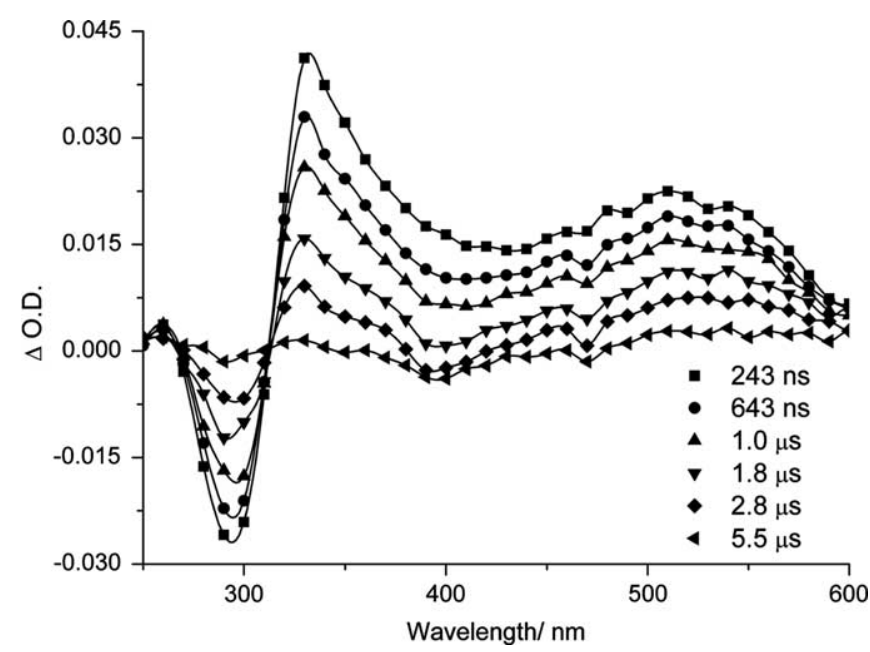

Fig. 2. Transient absorption spectrum observed following flash photolysis $\left(\lambda_{\text {excitation }}=266 \mathrm{~nm}\right)$ of a solution of methyl 4-bromo-5-phenylisoxazole-3carboxylate $\left(3.3 \times 10^{-5} \mathrm{moldm}^{-3}\right)$ in cyclohexane. 
Table 1

Photophysical data for methyl 4-halo-5-phenylisoxazole-3-carboxylate in cyclohexane

\begin{tabular}{|c|c|c|c|c|c|c|c|c|c|c|}
\hline Compound & $\lambda_{\max }(\mathrm{abs})(\mathrm{nm})$ & $\epsilon\left(\mathrm{mol}^{-1} \mathrm{dm}^{3} \mathrm{~cm}^{-1}\right)$ & $\begin{array}{l}\lambda_{\max } \text { (fluor.) } \\
(\mathrm{nm})\end{array}$ & $\begin{array}{l}S_{1} \\
\left(\mathrm{~cm}^{-1}\right)\end{array}$ & $\phi_{\mathrm{F}}$ & $\begin{array}{l}\tau_{\mathrm{F}} \\
(\mathrm{ns})\end{array}$ & $k_{\mathrm{F}} \times 10^{9}\left(\mathrm{~s}^{-1}\right)$ & $\begin{array}{l}T_{1} \\
\left(\mathrm{~cm}^{-1}\right)\end{array}$ & $\begin{array}{l}\tau_{\mathrm{ph}} \\
(\mathrm{ms})\end{array}$ & $\begin{array}{l}T-T_{\max } \\
(\mathrm{nm})\end{array}$ \\
\hline 1 & 307 & 24200 & 344 & 30798 & 0.368 & 0.67 & 0.55 & 20619 & 60 & 330 \\
\hline 2 & 307 & 20580 & 344 & 30798 & 0.0440 & 0.49 & 0.090 & 20747 & 3.5 & 330 \\
\hline
\end{tabular}

cyclohexane solutions of $\mathbf{1}$ and $\mathbf{2}$ with the fourth harmonic of a pulsed Nd/YAG laser $(266 \mathrm{~nm})$, and in both cases see moderately intense transient absorptions in the 350-600 nm region, with an apparent maximum around $330 \mathrm{~nm}$ and a shoulder around $500 \mathrm{~nm}$. These were accompanied by bleaching of the ground state absorption. The lifetimes were measured in degassed solutions for compound $\mathbf{1}$ at 330 and $500 \mathrm{~nm}$, and, within experimental error, were identical $(2.5 \pm 0.3 \mu \mathrm{s})$, and matched recovery of the ground state absorption. When oxygen was admitted to the solutions, the lifetimes decreased $(<1 \mu \mathrm{s})$. The transient absorptions with both $\mathbf{1}$ and $\mathbf{2}$ are assigned to the isoxazole triplet state since they follow first-order decay kinetics, they are quenched by oxygen, and on decay they regenerate the ground state. The triplet-singlet difference spectra of $\mathbf{2}$ is given in Fig. 2, while all photophysical data for the two compounds are given in Table 1. Because of overlap of the highest energy triplet band with the strong ground state absorption, the true triplet maximum is probably $<330 \mathrm{~nm}$.

To study the effect of solvent on this transition, the spectra of $\mathbf{1}$ and $\mathbf{2}$ were also run in ethanol. However, although the absorption spectra were similar in cyclohexane and ethanol, dramatic differences were observed in the fluorescence spectra in the two solvents (Fig. 3), with the highly structured emission in cyclohexane, being completely lost in ethanol solution. This change in structure with solvent was most pronounced over the region $0-1 \%$ ethanol. Since only minor changes in dielectric constant are expected in this re-

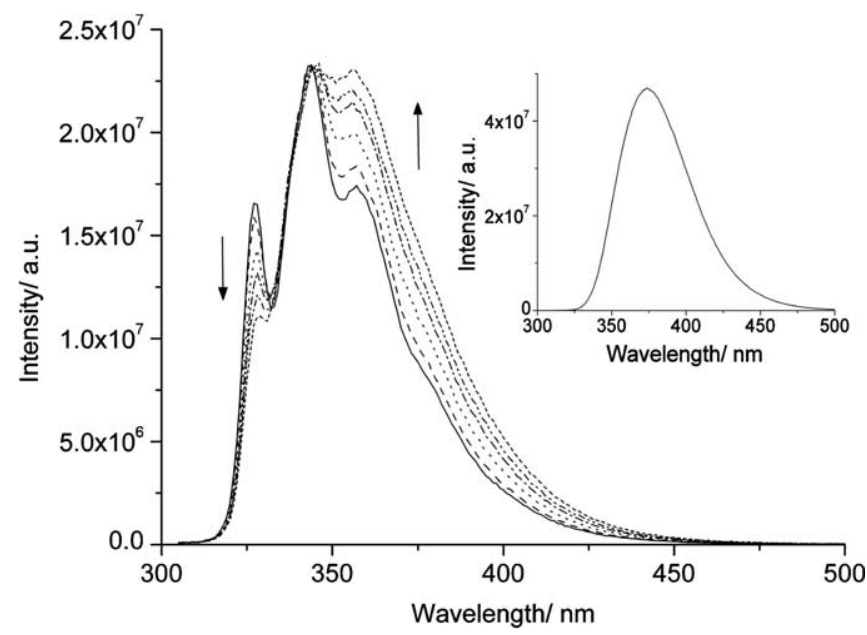

Fig. 3. Fluorescence spectra of isoxazole $1\left(1.0 \times 10^{-5} \mathrm{moldm}^{-3}\right)$ in cyclohexane solution (full line) and with increasing amounts of ethanol: $0.1 \%, 0.3 \%, 0.5 \%, 0.7 \%$ and $1 \%$. Excitation was at the absorption maximum $(307 \mathrm{~nm})$. Inset: fluorescence spectrum in ethanol solution. gion [24], it is unlikely that this is simply due to an effect of change in solvent polarity on the emission, and we suggest that this results from a specific interaction between ethanol and the isoxazoles. The nitrogen-oxygen bond in isoxazoles imparts a bipolar character [18,25], which may favour ethanol binding to these atoms. In support of this, we note that complexation between isoxazoles and water has been indicated from microwave spectroscopy [26], and a bifurcated hydrogen bond structure suggested from all-atom force field calculations [25]. The formation of this complex is likely to have implications on the photochemistry of isoxazoles, and may explain the reported differences in behaviour of these compounds on photolysis in alcohols and in other solvents [27]. It is also likely to have implications on the thermal reactivity of these compounds in solution in hydrogen bond donating solvents. Although the theoretical studies imply interaction of one hydrogen bond donor molecule with each isoxazole, from the ratio of ethanol to isoxazole concentration several molecules of alcohol must be involved. Future studies will attempt to further characterise these interactions.

\section{Conclusion}

We have provided a detailed photophysical characterisation of two 4-halo-5-phenylisoxazoles, which we feel provides a strong base for understanding the photoreactivity of these compounds. Both the lowest singlet and triplet states are suggested to have $\pi, \pi^{*}$ character. In the presence of ethanol, marked changes in the fluorescence spectrum are observed and attributed to the formation of hydrogen bonded complexes. These may have implications for the mechanistic behaviour of isoxazoles in these solvents.

\section{Acknowledgements}

We are grateful to Dr. J. Seixas de Melo and J. Pina for the determination of fluorescence lifetimes. One of us (SMF) thanks FCT for the award of a Postdoctoral Fellowship. We are grateful to FCT, POCTI and FEDER for further financial support.

\section{References}

[1] S.A. Lang, Jr., Y.-i. Lin, in: A.R. Katritzky, C.W. Rees, (series Eds.), K.T. Potts (Ed.), Comprehensive Heterocyclic Chemistry, vol. 6, Part 4B, Pergamon, Oxford, 1984 (Chapter 4.16).

[2] K. Naka, E. Horii, Y. Chujo, Polym. J. 32 (2000) 73.

[3] R. Iglesias, J.L. Serrano, T. Sierra, Liquid Crystals 22 (1997) 37.

[4] O. Buchardt, Photochemistry of Heterocyclic Compounds, Wiley, New York, 1976. 
[5] M. D'Auria, Heterocycles 50 (1999) 1115.

[6] P. Pino, G. Speroni, V. Fuga, Gazz. Chim. Ital. 84 (1954) 759.

[7] A.K. Murthy, K.S.R.M. Rao, N.V.S. Rao, Aust. J. Chem. 21 (1968) 2315.

[8] I.C. Walker, M.H. Palmer, J. Delwiche, S.V. Hoffmann, P.L. Vieora, N.J. Mason, M.F. Guest, M.-J. Hubin-Franskin, J. Heinesch, A Giuliani, Chem. Phys. 297 (2004) 289.

[9] M.H. Palmer, R.H. Findlay, R.G. Egdell, J. Mol. Struct. 40 (1977) 191.

[10] K. Jug, J. Org. Chem. 48 (1983) 1344.

[11] H. Berger, A.E. Siegrist, Helv. Chim. Acta 62 (1979) 779.

[12] T.M.V.D. Pinho e Melo, C.S.J. Lopes, A.M.d'A. Rocha Gonsalves, R.C. Storr, Synthesis 5 (2002) 605.

[13] R.S. Becker, J. Seixas de Melo, A.L. Maçanita, F. Elisei, J. Phys. Chem. 100 (1996) 18683.

[14] G. Striker, V. Subramaniam, C.A.M. Seidel, A. Volkmer, J. Phys. Chem. B 103 (1999) 8612.

[15] S. Califano, F. Piacenti, G. Speroni, Spectrochim. Acta 15 (1959) 86.

[16] A.R. Katritzky, A.J. Boulton, Spectrochim. Acta 17 (1961) 238.

[17] A.A. El-Azhary, H.U. Suter, J. Phys. Chem. 99 (1995) 12751.
[18] P. Grünanger, P. Vita-Finzi, in: E.C. Taylor (Ed.), A. Weissberger (Founding Editor), The Chemistry of Heterocyclic Compounds, Wiley Interscience, New York, 1991, Part 1 (Chapter 1).

[19] S.F. Mason, J. Chem. Soc. (1959) 1240.

[20] M.P. Fülscher, K. Andersson, B.O. Roos, J. Phys. Chem. 96 (1992) 9204.

[21] J.M. Oliva, M.E.D.G. Azenha, H.D. Burrows, R. Coimbra, J.S. Seixas de Melo, M.L. Canle, M.I. Fernández, J.A. Santaballa, L. Serrano-Andrés, ChemPhysChem 6 (2005) 306.

[22] J.B. Birks, Photophysics of Aromatic Molecules, Wiley-Interscience, London, 1970, pp. 208-211.

[23] L.J. Darlage, T.H. Kinstle, C.L. McIntosh, J. Org. Chem. 36 (1971) 1088.

[24] L. Hartshorn, C.C. Harris, J.A. Hey, T.I. Jones, A.G. Milligan, International Critical Tables of Numerical Data. Physics, Chemistry and Technology, vol. VI, McGraw-Hill, New York, 1929, p. 81.

[25] N.A. McDonald, W.L. Jorgensen, J. Phys. Chem. B 102 (1998) 8049.

[26] S. McGlone, P. Moreschini, T.K. Ha, A. Bauder, Mol. Phys. 99 (2001) 1353.

[27] T. Sato, K. Tamura, K. Maruyama, O. Ogawa, T. Imamura, J. Chem. Soc., Perkin Trans. 1 (1976) 779. 